\title{
POLÍTICAS PÚBLICAS CULTURAIS PARA AS INFÂNCIAS CEARENSES: ANÚNCIO DE NOVOS VENTOS?
}

\section{Cultural Public Policies for Children in Ceará: Announcement of New Winds?}

Políticas Públicas Culturales para la Niñez Cearense: ¿Anuncio de Nuevos Vientos? Politiques Culturelles Publiques pour les Enfants dans l'État du Ceará, Brésil : Un Nouveau
Vent Souffle?

10.5020/23590777.rs.v20iEsp1.e8877

\section{Érica Atem Gonçalves de Araújo Costa 9 iD}

Professora do Curso de Psicologia da Universidade Federal do Ceará (UFC). Doutora em Educação Brasileira pela Universidade Federal do Ceará (UFC).

\section{Andrea Pinheiro Paiva Cavalcante}

Professora do Curso de Sistemas e Mídias Digitais da Universidade Federal do Ceará (UFC). Doutora em Educação Brasileira pela UFC.

\section{Resumo}

A relação entre infância e políticas públicas brasileiras, historicamente, aparece sob a insígnia da (in)visibilidade, pela ausência de prioridade e/ ou pelo fato de as crianças não figurarem nessas ações como sujeitos ativos. Este artigo discute essa relação a partir da emergência de políticas públicas no âmbito da cultura em Fortaleza, especificamente o Edital de Apoio a Projetos de Cultura Infância 2016, lançado pela Secretaria de Cultura do Estado do Ceará (Secult). Pretendeu-se: a) evidenciar as possibilidades de outras cenas para/com as crianças no âmbito da cultura; b) analisar as relações entre infância e cultura presentes nas propostas e c) conhecer a avaliação dos proponentes sobre o edital. Como referencial teórico, optou-se pelo campo interdisciplinar dos novos estudos da infância. Como estratégias de produção dos dados, realizaramse entrevistas semiestruturadas com os proponentes, categorização dos formulários dos projetos e análise do referido edital. A partir da análise conjunta dos dados, pode-se perceber que a possibilidade de outras cenas para/com as crianças aparece relacionada aos diversos níveis de participação das crianças. As relações entre infância e cultura se expressam na variedade das áreas contempladas: artes visuais, teatro, dança e música, assim como na existência de diferentes formas de vinculação dos proponentes com o campo da infância. Por fim, os proponentes possuem uma visão positiva do edital, em consonância com a linguagem afirmativa das infâncias presente no documento. Concluiu-se que as relações entre infância e políticas públicas, no caso do edital, oportunizaram aos atores-adultos ampliar experiências estético-políticas junto às crianças em diversas áreas. Identificou-se, entretanto, a existência de limitações, que passam pela demora na liberação dos recursos, pela ausência de uma ação articulada entre os diversos proponentes sob a coordenação da Secult e, ainda, pela descontinuidade da iniciativa. Desse modo, a presença efetiva das crianças como agentes sociais atuantes nas cenas culturais permanece em disputa e por conquistar.

Palavras-chave: infâncias; políticas públicas; cultura.

\section{Abstract}

The relationship between childhood and Brazilian public policies, historically, appears under the banner of (in)visibility, due to the lack of priority and/or the fact that children do not appear in these actions as active subjects. This article discusses this relationship based on the emergence of public policies in the field of culture in Fortaleza, specifically the Public Notice for the Support of Childhood Culture Projects 2016, launched by the Secretary of Culture of the State of Ceará (Secult). It was intended: a) to highlight the possibilities of other scenes for/with children in the context of culture; b) to analyze the relations between childhood and culture present in the proposals and c) to know the evaluation of the proposers on the public notice. As a theoretical framework, the interdisciplinary field of new childhood studies was chosen. As data production strategies, semi-structured interviews were conducted with the proponents, categorization of 
the project forms and analysis of the notice mentioned above. From the joint analysis of the data, it can be seen that the possibility of other scenes for/with children appears related to the different levels of children's participation. The relationships between childhood and culture are expressed in the variety of areas covered: visual arts, theater, dance, and music, as well as in the existence of different ways of linking proponents with the field of childhood. Finally, the proponents have a positive view of the public notice, in line with the affirmative language of the children present in the document. It was concluded that the relations between childhood and public policies, in the case of the public notice, allowed adult actors to expand aesthetic-political experiences with children in different areas. However, it was identified the existence of limitations, which include the delay in the release of funds, the absence of articulated action between the various proponents under the coordination of Secult, and, also, the discontinuity of the initiative. Thus, the effective presence of children as social agents active in cultural scenes remains in dispute and to be conquered.

Keywords: childhood; public policy; culture.

\section{Resumen}

La relación entre niñez y políticas públicas brasileñas, históricamente, aparece bajo la insignia de la (in)visibilidad, por la ausencia de prioridad y/o por el hecho de los niños no participaren en estas acciones como sujetos activos. Este trabajo discute esta relación a partir de la emergencia de políticas en el ámbito de la cultura en Fortaleza, específicamente el Edicto de Apoyo a Proyectos de Cultura Niñez 2016, lanzado por la Secretaria de Cultura del Estado del Ceará (Secult). Posibilidades de otras escenas para/con los niños en el ámbito de la cultura; b) analizar las relaciones entre niñez y cultura presentes en las propuestas y c) conocer la evaluación de los proponentes sobre el edicto. Como referencial teórico, se decidió por el campo interdisciplinar de los nuevos estudios de la niñez. Como estrategias de producción de los datos, fueron realizadas entrevistas semiestructuradas con los proponentes, categorización de los formularios de los proyectos y análisis del referido edicto. A partir del análisis conjunta de los datos, se pudo percibir que la posibilidad de otras escenas paral con los niños aparece relacionada a los distintos niveles de participación de los niños. Las relaciones entre niñez y cultura se expresan en la variedad de las áreas contempladas: artes visuales, teatro, danza y música, así como en la existencia de distintas formas de enlace de los proponentes con el campo de la niñez. Por fin, los proponentes poseen una visión positiva de edicto, de acuerdo con el lenguaje afirmativo de las niñeces presente en el documento. Se concluyó que las relaciones entre niñez y políticas públicas, en el caso del edicto, dieron oportunidad a los actores-adultos ampliar experiencias estético-políticas junto a los niños en distintas áreas. Sin embargo, fue identificada la existencia de limitaciones, que pasan por la demora en la liberación de los recursos, por la falta de una acción articulada entre los distintos proponentes bajo la coordinación de la Secult y, aún, por la discontinuidad de la iniciativa. De este modo, la presencia efectiva de los niños como agentes sociales actuantes en las escenas culturales permanece en disputa y por conquistar.

Palabras clave: niñeces; politicas públicas; cultura.

\section{Résumé}

Historiquement, la relation entre l'enfance et les politiques publiques brésiliennes, apparaît sous le signe de la (in) visibilité, en raison du manque de priorité et / ou du fait que les enfants n'apparaissent pas dans ces actions comme des sujets actifs. Cet article traite de cette relation basée sur l'émergence de politiques publiques dans le domaine de la culture à Fortaleza (Brésil). En particulier, l'avis public relatif aux Projets de Soutien de Culture et Enfance 2016, lancé par le Secrétaire à la culture de l'État du Ceará (Secult). On a eu l'objectif $\grave{a}$ : a) mettre en évidence les possibilités d'autres scènes pour / avec les enfants dans le contexte de la culture ; b) analyser les relations entre enfance et culture présentes dans les propositions et c) connaître l'évaluation des proposants sur l'avis public. Comme cadre théorique, le domaine interdisciplinaire des nouvelles études sur l'enfance a été choisi. À titre de stratégies de production de données, des entrevues semi-structurées ont été menées avec les proposants, bien comme la catégorisation des formulaires de projet et, finalement, l'analyse de l'avis public susmentionné. De l'analyse conjointe des données, on a pu voir que la possibilité d'autres scènes pour / avec des enfants apparaît liée aux différents niveaux de participation des enfants. Les relations entre l'enfance et la culture s'expriment dans la variété des domaines couverts : les arts visuels, le théâtre, la danse et la musique, ainsi que dans l'existence de différentes façons de relier les partisans au domaine de l'enfance. Enfin, les proposants ont une opinion positive de l'avis public, conformément au langage affirmatif des enfants présents dans le document. Il a été conclu que les relations entre l'enfance et les politiques publiques, dans le cas de cet avis public, ont donné aux acteurs adultes la possibilité d'élargir les expériences pas seulement esthétiques, mais aussi politiques avec les enfants dans différents domaines. Cependant, des limitations ont été identifiées : le retard dans le déblocage des fonds, l'absence d'une action articulée entre les différents proposants coordonnés par Secult et, aussi, la discontinuité de l'initiative. Ainsi, la présence effective des enfants comme agents sociaux actifs sur les scènes culturelles reste contestée et à accomplir.

Mots-clés : enfance; politiques publiques; culture. 
Este artigo discute a relação infância e (in)visibilidade a partir da emergência de políticas públicas no âmbito da cultura na cidade de Fortaleza, especificamente no Edital de Apoio a Projetos de Cultura Infância 2016, lançado pela Secretaria de Cultura do Estado do Ceará (Secult). A problemática geral do texto alinha-se à perspectiva dos novos estudos da infância, em suas expressões após 1980, quando se reconhece o problema da visibilidade, ou invisibilidade, das infâncias em suas ambiguidades, variações conceituais e históricas (Qvortrup, 2014), e sua emergência como categoria geracional na modernidade. Segundo Sarmento (2004), identifica-se, em exercício na modernidade, um conjunto de normas, atitudes e prescrições, institucionalizadas ou não, que atravessam os modos de vida das crianças, processo que identificou como administração simbólica da infância, e que incide desde a sua mobilidade urbana até o que podem ou não comer, por exemplo.

Um dos efeitos do governo da infância desde a modernidade será a regulação de sua presença no espaço público, ficando às crianças reservado papéis no âmbito da família e da escola. Se, por um lado, surge um conjunto de saberes de peritos/especialistas que passam a se ocupar da infância como objeto de preocupação, por outro lado, essa visibilidade é também acompanhada de regiões de sombra, uma vez que as crianças ficarão destinadas a uma espécie de moratória, até serem consideradas aptas a uma participação social plena. Se a concepção das crianças como sujeito de direitos marca, na contemporaneidade, outro plano regulador através do qual se dá a administração simbólica da infância, ainda é preciso considerar que o processo de globalização (infância global) acentua as desigualdades como marcador da condição social das infâncias contemporâneas, sendo necessário compreender seus múltiplos efeitos (Sarmento, 2004).

Quando se trata das infâncias pobres brasileiras, por exemplo, o espaço público (sobretudo a vivência na rua) será interpretado como fonte de perigo, marcando-as como perigosas e indesejadas a quem se deve compensar ou corrigir. Portanto, uma visibilidade perversa que expõe as crianças como "delinquentes", "faltosas" e "carentes" e as silenciam em seus direitos. Dessa forma, para marcar essa tensão própria à constituição da infância como categoria geracional distinta da vida da adulta e plural, adota-se a grafia (in)visibilidade.

Entende-se que, no âmbito das políticas culturais, a proposta do Edital de Apoio a Projetos de Cultura Infância 2016 abriu a possibilidade de investigar iniciativas em que as crianças e as infâncias aparecem como eixo principal, em consonância com os dispositivos legais, como a Constituição Federal (1988), o Estatuto da Criança e do Adolescente de (Lei n. 8.069, 1990) o Plano Estadual de Cultura (Lei n. 16.026, 2016), o Marco Legal da Primeira Infância (Lei n. 13.257, 2016) e o Plano Nacional de Cultural (Lei n. 12.243, 2010).

Caracteriza-se, a seguir, o Edital de Apoio a Projetos de Cultura Infância 2016, de modo a situar o leitor diante do que se defende ser uma possibilidade de novos ventos e, dessa forma, justificar a importância de considerar esse documento como objeto de pesquisa e possibilitar compreender, por certo ângulo, a questão da (in)visibilidade da infância. Esse edital emerge como iniciativa da Secult com a premissa de reconhecer as crianças como "indivíduos autônomos, cidadãos e detentores de direitos, promovendo a infância como categoria social e cultural" (p. 02). O edital está em consonância com outros dispositivos legais que dispõem sobre a importância de desenvolver ações culturais para a infância.

Através do Edital de Apoio a Projetos de Cultura Infância 2016 foram aprovados 26 projetos, contemplando as diferentes infâncias existentes no território cearense, divididos em três categorias: "Criação, produção, circulação e fruição", "Formação e pesquisa" e "Memória cultural", com recursos que variaram de $\mathrm{R} \$ 32.000,00$ a $\mathrm{R} \$ 43.000,00$. O edital estabeleceu entre os seus objetivos "democratizar o acesso da criança à arte e à cultura de forma equânime, contemplando as diferentes infâncias presentes em todo o território cearense e ofertar às crianças bens e serviços artísticos que superem os padrões e modelos impostos pela cultura de massa" (p. 02). As aprovações foram igualmente distribuídas, considerando a origem do proponente, se interior ou capital, e as categorias, com 14 projetos na categoria 1 ("Criação, produção, circulação e fruição"), 6 projetos na categoria 2 ("Formação e pesquisa") e 6 projetos na categoria 3 ("Memória cultural").

A fim de contemplar as discussões propostas, a primeira seção do artigo aborda a relação histórica entre infância, (in) visibilidade e políticas públicas, de modo a situar minimamente esse campo de problematização para o caso da realidade brasileira e cearense. Na segunda seção, a abordagem da relação infâncias, crianças e políticas é considerada em um recorte específico: o âmbito da cultura e suas intersecções com as noções de crianças produtora de cultura e sujeitos de direitos. Na terceira seção, apresenta-se o delineamento metodológico, justificando a realização de um estudo qualitativo e as estratégias de produção e análise dos dados. O tópico da discussão e da análise dos resultados enfatizam mutuamente os dados referentes aos documentos e às entrevistas, tentando entender a relação entre infância e política pública no contexto de produção do Edital de Apoio a Projetos de Cultura Infância 2016, articulando as visões de infância e cultura em exercício, assim como as limitações apontadas pelos proponentes. Na conclusão e considerações finais, reúnem-se os resultados, apontando desdobramentos para futuras investigações, aliando a temática ao campo maior de discussão das políticas públicas brasileiras para a infância. 


\section{A Visibilidade das Crianças e das Infâncias como uma Questão}

O percurso histórico em que a infância se torna objeto de conhecimento e alvo das políticas públicas, no Brasil, é longo e não linear. Constitui-se por paradigmas legais diferentes, na tensão entre uma infância tida como problema social e econômico a ser evitado e uma infância sujeito de direitos (Cruz, Hillesheim, \& Guareschi, 2005; Passetti, 2000). Nessa descontinuidade histórica, expressam-se diferenças de prioridade e/ou (in)visibilidade, a partir das quais estão dispostos os termos das relações entre as políticas públicas e seus destinatários, aqui especificamente as crianças pobres (González, 2015; Sarmento, 2006). Elas se encontram nesse grupo de pouca ou nenhuma visibilidade em relação às políticas públicas num plano geral (Sarmento, Fernandes, \& Tomás, 2007).

A sociologia da infância tem pautado, recorrentemente, as diferenças entre os conceitos de infância e criança como uma questão para as análises contemporâneas, entendendo tal tarefa como necessária para desnaturalizar tais noções, comumente tratadas como sinônimas. Entende-se as crianças como agentes ativos, sujeitos históricos e de direitos, e a infância como categoria geracional (Castro, 2001; Sarmento, 2006). A condição das crianças como grupo e sujeitos psicológicos individuais coexiste, então, com a dimensão estrutural da infância como categoria geracional que define socialmente "o lugar das crianças" como sujeitos de um mesmo grupo etário e sujeito a normatizações. As crianças, por sua vez, em suas experiências de infância, são atravessadas por interseccionalidades que refletem o cruzamento do critério etário com as questões de gênero, raça/etnia, de classe, mostrando a complexidade dos processos de subjetivação infantis.

Admitindo as considerações de Qvortrup (2014) sobre ambiguidade e variação conceitual e histórica, presentes no tema da (in)visibilidade da infância e/ou das crianças, neste estudo, a relação entre infância, cultura e políticas públicas na cidade de Fortaleza está interligada à relação da criança com o espaço público/urbano e da gestão biopolítica da infância enquanto população (Cruz et al., 2005; Mantilla, Stolkiner, \& Minnicelli, 2017), a quem o estado deve prover e garantir direitos, inclusive a cultura.

Ao retomar os momentos históricos ocidentais estudados por Phillipe Ariès, Qvortrup (2014) os analisa,estes são analisados sob a ótica da existência de uma descontinuidade entre Idade média e a modernidade ocidental europeia no que diz respeito às crianças, qual seja: as crianças, no ocidente europeu, estavam presentes na cena pública, embora a infância como categoria geracional fosse invisível.

As sociedades modernas passam a regular e normatizar a presença/ausência da criança no espaço público segundo um prisma adultocêntrico (as crianças importam pelo que irão se tornar no futuro, quando forem adultas), o que Marchi e Sarmento (2017) debatem como processo de administração simbólica da infância, processo em franca transformação no mundo contemporâneo.

Autores brasileiros (Barbosa, Delgado, \& Tomás, 2016) chamam a atenção para a base anglo-saxã constituinte dos estudos da infância e da criança, na qual se apoiam as pesquisas brasileiras. É preciso ainda construir o campo singular dessa problemática quando se trata da realidade brasileira e latino-americana (Magistris, 2014). Sem esquecer que ambas as experiências de infância - brasileira e europeia - se articulam num plano normativo geral, ou seja, aquele que as define juridicamente como pertencendo a esse grupo geracional desde a Convenção Internacional dos Direitos da Criança (Unicef, 1989).

O problema da (in) visibilidade da infância e/ou das crianças, no sentido deleuziano, ou seja, aquilo que movimenta o pensamento e não necessariamente o que é absolutamente original (Deleuze \& Parnet, 1998), é tratado como uma questão ambígua e relacionada às tensões entre participação, proteção e presença das crianças na cena pública. Sua aproximação da discussão sobre as políticas culturais traz à tona o desafio do encontro intergeracional e da ocupação da cidade pelas crianças (Dias \& Ferreira, 2015; Sarmento, 2018), além das mudanças éticas para um enfrentamento do adultocentrismo (Barbosa, 2014; Francischini \& Fernandes, 2016) e de práticas sociais verticalizadas, nas quais a criança não é agente social atuante (Barbosa et al., 2016; Tomás, 2007).

A invisibilidade da infância e/ou das crianças, sobretudo daquelas moradoras de regiões periféricas, na cidade de Fortaleza, articula-se direta ou indiretamente ao seu status de capital com altas taxas de homicídios entre pessoas entre 10 a 19 anos. Segundo relatório do Comitê Cearense pela Prevenção de Homicídios na Adolescência [CCPHA] (2018), “(...) em Fortaleza, 189 meninos e meninas, de 10 a 19 anos, foram mortos nos sete primeiros meses de 2018” (p.14). As análises indicam que "a partir de 2017, o Ceará começou a vivenciar uma expansão da violência, que resultou em dois fenômenos: infantilização dos homicídios (com redução da idade das vítimas) e aumento das mortes violentas de mulheres” (p. 23).

Nesse contexto sócio-político, as (in)visibilidades da infância e/ou das crianças revelam-se: a) na sua exclusão, como criança de periferia e pobre, de um modo de subjetivação pautado na condição de sujeito de direitos; b) no fato dessa condição encontrarse, contraditoriamente, na dependência do aperfeiçoamento das instituições especializadas ou da des-espacialização da infância (Qvortrup, 2014), aspectos que designam a infância ao espaço privado e doméstico, distante da cidade e da vida pública; c) no ato perverso de marginalização das crianças que ocupam transgressoramente o espaço da cidade/da rua, uma vez que para elas não se garantem minimamente os direitos sociais previstos na normativa jurídica da proteção integral (Marchi \& Sarmento, 2017). 
Nesta pesquisa, as políticas públicas, especificamente no campo da cultura, subscrevem-se nesses contextos de lutas por direitos, revelando as mesmas ambiguidades. A possibilidade de outros regimes de visibilidade advém do fato da cultura ser uma área transversal e que pode dialogar com outros campos a que as políticas públicas têm se voltado no caso da infância - mesmo que insuficientemente-, como a saúde, a educação e a assistência (Morais, Carvalho, Magalhães, \& Pinto, 2015). Desse modo, a invisibilidade como problema/objeto de estudo permanece um desafio na realidade brasileira, coadunando com perspectivas como a que se considerou nesta pesquisa.

Em âmbito nacional, tais direitos estão assegurados a partir da Constituição Federal (Brasil, 1988) e pelo Estatuto da Criança e do Adolescente (Lei n. 8.069, 1990). Em âmbito internacional, o documento que normatiza os direitos das crianças é a Convenção Internacional dos Direitos da Criança (1989), da qual o Brasil é signatário.

A despeito de tais aparatos legais "que regularam a vida das crianças e padronizaram os modos de relação entre o Estado, as famílias e as crianças" (Marchi \& Sarmento, 2017, p. 953), muitas infâncias são invisíveis para essas normativas, especialmente as pobres e marginalizadas, geograficamente situadas no hemisfério sul.

Assim, um determinado tipo de infância, sendo considerado norma, não somente desclassifica todos os outros tipos no plano ideal, mas, mais grave, exclui, no plano empírico — da realidade social cotidiana — determinadas crianças dos direitos que lhes estão internacionalmente assegurados. Certas crianças seriam, assim, crianças apenas no plano jurídico. Desse modo, práticas e concepções de crianças que se afastam da normatividade definida pelas classes e grupos sociais dominantes podem levar a excluir certas crianças do próprio estatuto social reconhecido da infância: tematizados como "não crianças", os meninos de rua, por exemplo, sofrem dupla exclusão, dos direitos sociais básicos e do valor simbólico inerente ao seu reconhecimento como crianças. (Marchi \& Sarmento, 2017, p. 957)

A prioridade absoluta, preconizada no artigo 227 da Constituição Federal (1988), e o direito à provisão (artigos 06 17, 28, 29 e 31), proteção (artigos 08, 16, 17 e 19) e participação (artigos 03, 12, 13 e 14), garantidos pela Convenção Internacional dos Direitos da Criança (1989), não passam de "letra morta" para um contingente significativo de crianças brasileiras.

Dados da Síntese de Indicadores Sociais - SIS (Instituto Brasileiro de Geografia e Estatística [IBGE], 2017) indicam que $42 \%$ das crianças de 0 a 14 anos vivem na linha da pobreza, ou seja, sobrevivem com apenas US\$ 5,5 por dia (valor adotado pelo Banco Mundial para definir se uma pessoa é pobre). Para Marchi e Sarmento (2017), "as crianças são o grupo geracional mais afetado pelo aumento das desigualdades sociais fomentado pela globalização" (p. 958) e, por estarem excluídas da visão normativa da infância, são percebidas mais como patologia social do que sujeitos de direitos.

Partindo dessas considerações preliminares, este artigo se propõe: a) evidenciar as possibilidades de outras cenas para/ com as crianças no âmbito da cultura; b) analisar as relações entre infância e cultura presentes nas propostas e c) conhecer a avaliação dos proponentes sobre o edital.

\section{Percursos e Estratégias Metodológicas da Pesquisa}

Para atender aos objetivos, optou-se por uma pesquisa qualitativa, uma vez que se pretende compreender a relação entre infância e políticas públicas no âmbito da cultura. Em relação à produção de dados, buscaram-se métodos que contemplassem as especificidades da pesquisa qualitativa: análise documental e entrevistas semiestruturadas.

Para Minayo (2012), a pesquisa qualitativa tem características bem definidas:

O verbo principal da análise qualitativa é compreender. Compreender é exercer a capacidade de colocar-se no lugar do outro (...). Para compreender, é preciso levar em conta a singularidade do indivíduo, porque sua subjetividade é uma manifestação do viver total. Mas também é preciso saber que a experiência e a vivência de uma pessoa ocorrem no âmbito da história coletiva e são contextualizadas e envolvidas pela cultura do grupo em que ela se insere. (Minayo, 2012, p. 623)

Considerando o Edital de Apoio a Projetos de Cultura Infância 2016 em sua materialidade histórica, optou-se por pesquisar 6 (seis) formulários dos projetos aprovados pelo referido edital na categoria I, "Criação, produção, circulação e fruição", no município de Fortaleza.

As estratégias metodológicas seguiram as seguintes etapas: 1) sistematização e categorização de seis projetos aprovados no referido edital na categoria 1;2) seleção e análise de documentos relacionados ao Edital de Apoio a Projetos de Cultura Infância 2016 e à política pública para a infância do estado, a exemplo do Programa Mais Infância (Lei n. 16.856, 2019) e do Plano Estadual Cultura Infância (Lei n. 122, 2017); 3) realização de entrevistas com seis proponentes dos projetos aprovados na Categoria I.

A sistematização dos seis projetos aprovados na categoria "Criação, produção, circulação e fruição" incluiu, primeiramente, o acesso aos projetos, a partir da negociação com a Secult e a categorização das informações, foram 
organizadas em três eixos: (1) detalhes sobre o projeto (área, temática, tipo de atuação, território e local da apresentação); (2) participação da criança (faixa etária, papel da criança); e, por fim, (3) proponentes (formação, experiência com crianças).

Essa sistematização/categorização subsidiou a análise da identificação das temáticas predominantes das propostas, assim como das concepções de infância e cultura, ao que se somou à análise das entrevistas com os proponentes dos projetos, no total de seis entrevistas.

As entrevistas foram realizadas entre março e abril de 2018, momento em que foram visitadas as sedes de realização dos projetos. As visitas possibilitaram traçar a relação entre participação das crianças e ações realizadas, como também para perspectivar os impactos das ações na comunidade e conhecer os espaços-tempo em que os projetos acontecem e do que dependem. Os locais foram acordados com os proponentes, privilegiando, em sua maioria, o deslocamento dos pesquisadores até a sede das atividades dos projetos.

Foram ouvidos seis proponentes contemplados pelo edital por meio de entrevistas semiestruturadas, as quais foram concedidas por pessoas ligadas ao planejamento das ações e que, de alguma maneira, acompanharam a proposição e o lançamento do edital. As entrevistas foram gravadas e, posteriormente, analisadas, tendo em vista os objetivos da pesquisa e articulações teóricas com o campo de estudos das infâncias e das crianças.

Optou-se por um roteiro aberto e semiestruturado, de modo que os proponentes pudessem falar de outros temas não previstos, assim como articular como desejassem os pontos sugeridos. O roteiro contemplou quatro tópicos: (1) informações sobre o projeto (momento em que estava o projeto e o que havia sido feito; dificuldades; relação com à Secult); (2) proposição/ participação do edital (existência ou não de inflexões no que diz respeito às ações junto com crianças; motivações para inscrição no edital); (3) questões do trabalho em si (lugar da criança no projeto; expectativas; relação entre o desenvolvimento infantil e a cultura; o tipo de envolvimento das crianças). Como último eixo, foi importante pensar sobre: (4) desdobramentos e continuidade do trabalho dos proponentes com crianças. Embora a pesquisa tenha se constituído em várias etapas distintas, as análises foram sendo realizadas durante todo o processo, atentando à triangulação dos diferentes dados.

As entrevistas foram realizadas pessoalmente, nos endereços das sedes das instituições proponentes, com exceção de uma entrevista, que foi realizada em local indicado pela proponente. Os contatos foram feitos, primeiramente, por e-mail, com uma apresentação prévia da pesquisa e seus objetivos e, após resposta do proponente, detalhava-se o local e o horário das entrevistas.

\section{Resultados e Discussão}

\section{Os Efeitos Positivos do Edital}

De um modo geral, foram identificados segundo a natureza da proposta: um projeto de teatro, um projeto de artes visuais, dois projetos de dança, um projeto de música e um projeto de implantação de um parque criativo com brinquedos e esculturas.

O edital apresenta aspectos contemporâneos da discussão do campo de estudos da infância e das crianças ao "valorizar a diversidade cultural da infância cearense" (p. 3) em contraponto a uma imagem universal e normatizada, favorecendo o pertencimento comunitário e familiar das crianças como esteio de suas significações. A concepção de infância é considerada também em suas dimensões estéticas, éticas e políticas, e não se vincula a um calendário maturativo ao enfatizar "diferentes identidades e fases da infância e suas implicações culturais, educacionais, sociais e econômicas". (p. 3).

A noção de "cultura infância" é central na proposta, sendo assim definida:

(...) um fenômeno social e humano de múltiplos sentidos que abrange diretamente ou indiretamente a categoria geracional de 0 (zero) a 12 (doze) anos de idade, perpassando por toda sua extensão antropológica, sociológica, política, ética, estética, simbólica, produtiva e econômica e respeitando as peculiaridades das diferentes fases da infância. A criança, dentro desse escopo, é entendida como sujeito histórico-cultural e de direitos com prioridade absoluta, produtor de cultura e capaz de desenvolver suas diversas linguagens. O brincar se destaca como a sua principal linguagem e nesse sentido, a criança constrói suas compreensões e significações do mundo e de si própria e interage com outras crianças e com os outros membros da sociedade. De igual relevância, deve-se considerar as manifestações artísticas e culturais produzidas e fruídas pela criança, com a criança e para a criança. (Edital de Apoio a Projetos de Cultura Infância 2016, p. 2)

Os objetivos do edital costuram outros aspectos inovadores do texto, como a noção de participação infantil e a diversidade das experiências de infância cearense. Embora carreguem um significado complexo e tenham condições específicas para sua efetivação como práticas, o edital funciona tanto como horizonte para aqueles que tentam iniciar ações nesse âmbito como podem ajudar na permanência e manutenção de projetos que já funcionam segundo esses eixos ético-políticos no que diz respeito à construção social das infâncias cearenses, sobretudo pobres. 
Perceberam-se diferenças no modo de impacto que o edital promove quando relacionado à história de cada grupo contemplado. O efeito positivo do edital para ONGs e projetos com experiência junto ao público infantil - os projetos de música e teatro - se deu mais pela possibilidade de manutenção de trabalhos consolidados e com necessidade de reconhecimento dos grupos do que pela abertura de um campo de trabalho com as crianças.

O edital veio muito como esse respiro para a gente no sentido desse público, principalmente em relação ao projeto. É isso, às vezes um edital contempla a manutenção daquela atividade, por exemplo, os professores, o material a ser usado, mas não contempla outras coisas que uma escola precisa. (Trecho da entrevista com proponente do Projeto Música 27/03/2018)

O Projeto Música já tinha experiências com a política de editais, tendo como foco atividades e intervenções com as crianças. Nesse caso, o "respiro" significa manter práticas para crianças em situação de vulnerabilidade e um plano de formação contínuo.

Outro aspecto citado e que divide os significados atribuídos pelos grupos ao edital é como a política pública pode reservar condições de resistência aos agentes culturais quanto às demandas do mercado do entretenimento, casos do Projeto Teatro 1 e Projeto Dança 1. Mas a manutenção dos projetos, embora fosse levantada como positiva, revelou a prática de adaptações nas atividades habituais (Projeto Dança 2). Tal fato parece mais relacionado à corrida por financiamento e a observações das exigências de cada edital, sugerindo uma mudança lenta quanto ao deslocamento do lugar das crianças de objeto das ações para interlocutoras e partícipes dos processos de criação.

No Projeto Música, mesmo que esse deslocamento não tenha se revelado por completo, como potencialmente foi descrito no edital ("considerar as manifestações artísticas e culturais produzidas e fruídas pela criança, com a criança e para a criança") (p. 02), pode-se perceber abertura para novas experimentações e criações.

\section{Relações entre Infância e Cultura}

Observa-se, pelas áreas contempladas nos projetos, uma variedade de linguagens, a saber: arte visual, teatro, dança e música, que coadunam com a noção da infância como experiência e da criança como produtora de cultura. Vê-se que, embora cada projeto esteja vinculado a uma área, de forma a facilitar sua descrição e identificação, alguns assumem a condição de transitar entre artes distintas, como é o caso do projeto da música que está relacionado à dança e do projeto da dança que se aproxima da linguagem teatral, articulação importante quando se recorda a curricularização a que as práticas destinadas às crianças estão habituadas em ambientes escolarizados ou pedagogizados.

O objetivo da produção do "CarRuagem Infantil" é fazê-lo circular pelas ruas da periferia de Fortaleza, visitando escolas, associações, instituições de classe etc., descentralizando o ensino da arte e educação e pulverizando os conhecimentos onde se mais necessita. (Trecho do formulário resumo do Projeto Artes Visuais)

A previsão de realizar as atividades em articulação com escolas e equipamentos de cultura da cidade, como descritos nos formulários, incluindo ações intermediárias e também a realização dos espetáculos e culminâncias dos projetos, revelou diferentes formas de impacto na comunidade e na cidade. Pela sistematização das informações, percebe-se que, em termos de localização, os projetos concentravam-se em espaços institucionais, como escolas de dança, teatro e música, privilegiando espaços públicos para a culminância das ações, aspecto previsto no edital.

A questão da localização abrange, portanto, questões muito maiores que somente a dimensão geográfica ou física da cidade. As cidades apresentam-se divididas por fronteiras sociais, muitas vezes intransponíveis por questões de estereótipos e/ou pela presença de índices de vulnerabilidade e violência urbana, excluindo certos grupos urbanos. A tentativa de ocupar esses equipamentos públicos repercute positivamente diante da ausência de uma agenda cultural para as crianças nas cidades, assim como, ao mesmo tempo, revela a dificuldade para projetos em bairros periféricos da cidade e de baixo IDH, a exemplo do projeto de música, pois a violência nas regiões periféricas tem restringido a mobilidade de crianças e adolescentes.

É possível perceber nos formulários o quanto os projetos apresentam-se como desafiadores ao estabelecimento de diálogo com as crianças pela mediação de espaços públicos e práticas que as possibilitem ocupar a cidade.

O projeto Teatro trata-se de uma ação teatral integrada (Formação, Apresentação Teatral e Debate) voltada para o público infanto-juvenil e que irá interagir com a escola e agentes teatrais das cidades que receberão essa atividade. (...) Entender o Teatro Infantil como algo que é só para crianças é o que provoca em nós (...) certa insatisfação. Esse é um fazer artístico que, em geral, carrega certos rótulos e é considerado menor, reafirmando todo o preconceito que há em relação às crianças e ao universo infantil e, por isso mesmo, um aprofundamento em técnicas ou métodos específicos de atuação não é visto como necessário. Contrariando esse processo (...), buscamos uma comunicação cênica com crianças que pode e deve ser utilizada 
em qualquer gênero teatral e para qualquer público, mas que tem na criança e no universo infantil um foco que impulsiona nossa pesquisa e criação. (Trecho do formulário resumo do Projeto Teatro)

Pela análise do edital, identifica-se que a preocupação com a relação cultura e cidade parece se explicitar pela presença de pontuação extra para projetos que contemplassem "territórios prioritários", ou seja, "projetos que contemplem ações realizadas em municípios do Programa Mais Infância e/ou em bairros do Ceará Pacífico" (Edital de Apoio a Projetos de Cultura Infância 2016, 2016, p. 14). Trata-se de projeto do governo do estado com vistas à redução dos índices de violência e que prevê um conjunto de ações articulando as diversas esferas do governo.

Outro aspecto importante é o estímulo ao "uso de espaços culturais e logradouros públicos das cidades cearenses que ofereçam condições de ocupação democrática para o exercício do brincar, a convivência intergeracional e familiar, a memória cultural, o protagonismo infantil e o usufruto das artes" (Edital de Apoio a Projetos de Cultura Infância 2016, 2016, p. 3), momento em que aparece explicitamente a relação cultura e cidade, sugerindo a ocupação pela criança do espaço público e urbano e com possibilidades de transformar e ser transformada pela mediação das ações dos projetos.

Em sua vinculação com outras políticas públicas para a infância no Ceará, a exemplo do Programa mais Infância e seus eixos de ação, percebeu-se que a Secult, proponente do edital em análise, não é mencionada como possível agente de atuação junto ao programa. A ausência parece indicar uma diferença entre as concepções de infância e desenvolvimento infantil em vigor. Resumidamente, o Programa Mais Infância Ceará (2019), idealizado pelo Gabinete da Primeira-dama do estado do Ceará, prioriza o desenvolvimento infantil. O programa está organizado a partir dos seguintes pilares: Tempo de Crescer, Tempo de Brincar e Tempo de Aprender.

O Mais Infância Ceará (2019) parte do entendimento de que "reconhecer o desenvolvimento na primeira infância como um dos investimentos com o retorno mais seguro que a gestão pública e as famílias podem empreender, no sentido de construir vidas produtivas capazes de impulsionar melhorias individuais e sociais, é a chave do futuro" (p. 37).

Desse modo, pode ser oportuno compreender como as práticas culturais e as culturas infantis (objeto do Edital de Apoio a Projetos de Cultura Infância 2016) podem ou não se articular com os discursos e práticas do ponto de vista da promoção do desenvolvimento infantil, sem distanciar-se da compreensão da criança como sujeito de direitos e produtora de cultura.

\section{Possibilidade de Novas Cenas para/com as Crianças}

De um modo geral, pelas entrevistas, identifica-se que o Edital de Apoio a Projetos de Cultura Infância 2016 oportunizou a atores-adultos que ampliassem suas experiências estético-políticas junto às crianças. $\mathrm{O}$ que se relaciona fortemente com diversidade de áreas contempladas (teatro, arte visual, dança, música e implantação de um parque criativo com brinquedos e esculturas).

Pelos formulários, especificamente pela análise do campo "histórico do proponente", percebemos que, embora alguns proponentes não atuassem em campos profissionais relacionados às crianças, exemplo do Projeto Dança 1 e dos Projetos Artes Visuais e Parque Criativo, as propostas demonstraram-se as mais arrojadas quanto a projetar a criança como interlocutora e atuante no processo de criação e experimentação dos agentes culturais e artistas.

O projeto propõe um período de pesquisa com artistas-colaboradores, levantamento de material e pesquisa em tribos resistente no Ceará (como os Jenipapo-Kanindé em Aquiraz e os Tapebas em Caucaia) e aberturas de processos-cena com crianças para construirmos juntos a imagem indígena, sem as 'caricaturas' da grande mídia e da indústria do entretenimento. (Trecho do formulário resumo do Projeto Dança 1)

Quanto à participação das crianças, elas aparecem como coautoras no Projeto Dança 1 e no Projeto Arte Visuais. Neste último, a descrição enfatiza essa participação na brincadeira e na arte.

A proposta prevê a realização de cinco minicursos / oficinas, nos bairros Cais do Porto, Curió, Serrinha, Vila Velha e Autran Nunes, totalizando 80 horas/aula, que beneficiarão diretamente até 100 crianças, no ensino de técnicas de produção de pintura artística e de arte urbana, tanto na realização de ações quanto na construção de ferramentas/equipamentos que possibilitem o despertar criativo, gerando inclusão, ampliação da autoestima e geração acesso ao lúdico através da arte. Outro fator importante é através do brincar no fazer artístico, desenvolver o olhar para o espaço público, o lugar onde se vive, buscando por meio das ações, requalificando visualmente a periferia da capital cearense, transformado as ruas e vielas em espaços de arte e beleza. (Trecho do formulário resumo do Projeto Artes Visuais) 
Nesses dois casos, as experiências da maternidade e da paternidade foram citadas pelos proponentes, durante as entrevistas, como elemento significativo da construção de um diálogo com a criança, a partir de sua interferência nas atividades sem tantas reservas quanto a uma obra acabada e já definida de antemão.

O Projeto de Artes Visuais e de implantação de um parque criativo com brinquedos e esculturas, aprovados pelo mesmo proponente, incluía a intervenção no espaço urbano pensado a partir das crianças da periferia, tradicionalmente invisibilizadas. A intenção de trabalhar com crianças vem da experiência como artista urbano e também como pai. "As crianças precisam se relacionar com a cidade" (Trecho da entrevista com o proponente do Projeto Artes Visuais e Parque Criativo. 02/03/2018).

No Projeto Música e o no Projeto Teatro observa-se a possibilidade da presença de diferentes idades (elasticidade da indicação etária no caso dos espetáculos), ressignificando necessidades das crianças que, em outros momentos, são relatadas como obstáculos ao espetáculo (falas, entradas e saídas, choros, perguntas, interrupções).

A entrevista com a equipe do Projeto Teatro revelou uma perspectiva para além da produção de espetáculos, apontando articulação com outros grupos de teatro para a infância. Tal articulação provoca pensar o fazer teatral para criança na dimensão de uma produção educativa, para além do mero entretenimento - por isso a realização de espetáculos em escolas e atividades que envolvam os educadores como uma forma de ampliação do repertório cultural desses profissionais e das próprias crianças.

Esse projeto destaca a questão da experiência da infância pelas próprias crianças e das aprendizagens por processo de mediação que não apenas adultos, ou que dependam de sua centralidade e diretividade, repercutindo no seu deslocamento também como sujeito na relação com a criança.

É nesse sentido que se espera contribuir com experiências e reflexões que têm na criança sua inspiração e direcionamento. (...) Além disso, difundir um teatro infantil diferenciado, que foge da mera repetição de produtos da grande mídia, destacando-o como linguagem artística criativa, daí sua importância no desenvolvimento da criança e da formação de futuras plateias. (Trecho do formulário resumo do Projeto Teatro)

A especificação quanto à necessidade de comprovada experiência de, no mínimo, três anos de atuação no campo artístico, cultural e/ou no âmbito da infância (para pessoas físicas e jurídicas) sugere a potência do edital em mapear grupos e agentes culturais que, de alguma maneira, vêm realizando, mesmo que há pouco tempo, experiências no campo da infância, se caracterizando como dispositivo de abertura para trabalhos na área que não necessariamente estão consolidados na cena da cidade. Observa-se um plano de visibilidades mútuas, agentes culturais, adultos e crianças periféricas.

Por todos esses aspectos até aqui levantados, na definição da categoria I pelo edital percebe-se a ênfase em situar as crianças como interlocutoras ao se dizer "para e/ou com crianças, entendendo-as como criadoras, produtoras, mediadoras e apreciadoras" (Edital de Apoio a Projetos de Cultura Infância 2016, 2016, p. 2).

As crianças excluídas constituem o segmento priorizado nas propostas aprovadas no Edital de Apoio a Projetos de Cultura Infância 2016. Assim, muitas das ações apresentadas pelos proponentes situaram-se em territórios de alta vulnerabilidade social e buscaram alcançar crianças da região periférica da cidade, que, de modo geral, estão à margem das ofertas de produção cultural para crianças.

\section{Considerações Finais}

Ainda que o Edital de Apoio a Projetos de Cultura Infância 2016 se constitua como um avanço em termos de políticas culturais para a infância, os proponentes apontaram diversas limitações que passam pela demora na liberação dos recursos, pela ausência de uma ação articulada sob a coordenação da Secult e ainda pela descontinuidade da iniciativa. Proposto em 2016, até início de 2019 não foram lançados novos editais na perspectiva da cultura infância, embora tenha havido mobilização junto à Secult por parte dos proponentes na tentativa de assegurar a continuidade dessa política pública. Vale lembrar que essa articulação em rede, envolvendo a Secult e os agentes culturais, foi responsável pela criação do próprio edital.

Identifica-se como uma das contribuições do Edital de Apoio a Projetos de Cultura Infância 2016 a oportunidade de participação de crianças da periferia em muitas das proposições, muitas vezes se constituindo a única aproximação de tais crianças com produções culturais, sem que para isso tenha que se deslocar do lugar onde mora. Em tais territórios, em muitos casos dominados por organizações criminosas, não estão assegurados o amplo direito de ir e vir, inclusive, de crianças e jovens.

O campo das políticas públicas para a infância, a partir do paradigma legal da proteção integral, mantém as ambiguidades, como a tensão proteção/participação e a perspectiva da competência como condição de exercício de cidadania. Por sua vez, o Edital de Apoio a Projetos de Cultura Infância 2016 parece encontrar brechas micropolíticas para o enfrentamento dessas ambiguidades quando estimula práticas num âmbito local da vida de crianças, ligado às suas riquezas culturais e grupos de pertença e comunidade e, portanto, sua diversidade identitária. 
Por um lado, a política cultural para a infância pode criar modos de debater sobre os direitos das crianças, a partir da contramão, do que é inesperado, uma vez que as crianças foram convidadas na condição de interlocutoras, o que constitui certa visibilidade. Por outro lado, no âmbito geral, a visibilidade efetiva das crianças como agentes sociais atuantes permanece em disputa e por conquistar.

\section{Referências}

Barbosa, M. C. S. (2014). A ética na pesquisa etnográfica com crianças: Primeiras problematizações. Práxis Educativa (Brasil), 9(1), 235-245.

Barbosa, M. C. S., Delgado, A. C., \& Tomás, C. A. (2016). Estudos da infância, estudos da criança: quais campos? Quais teorias? Quais questões? Quais métodos? Inter-Ação, 41(1), 103-122. DOI: 10.5216/ia.v40i3.35869

Brasil. (1988). Constituição da República Federativa do Brasil de 1988. Link

Castro, L. R. (Org.). (2001). Crianças e jovens na construção da cultura. Rio de Janeiro: NAU editora, FAPERJ.

Ceará. Secretaria de Cultura. (2016). Edital de Apoio a Projetos de Cultura Infância 2016. Link

Comitê Cearense pela Prevenção de Homicídios na Adolescência [CCPHA]. (2018). Cada vida importa: Relatório do primeiro semestre de 2017. Link

Cruz, L., Hillesheim, B., \& Guareschi, N. M. F. (2005). Infância e políticas públicas: Um olhar sobre as práticas psi. Psicologia \& Sociedade, 17(3), 42-49. DOI: 10.1590/S0102-71822005000300006

Deleuze, G., \& Parnet, C. (1998). Diálogos. São Paulo: Editora Escuta.

Dias, M. S., \& Ferreira, B. R. (2015). Espaços públicos e infâncias urbanas: A construção de uma cidadania contemporânea. Revista Brasileira de Estudos Urbanos e Regionais (RBEUR), 17(3), 118-133. DOI: 10.22296/2317-1529.2015v17n3p118

Francischini, R., \& Fernandes, N. (2016). Os desafios da pesquisa ética com crianças. Estudos de Psicologia (Campinas), 33(1), 61-69. DOI: 10.1590/1982-02752016000100007

González, R. S. (2015). Políticas públicas para a infância no Brasil: Análise do processo de implementação de um novo modelo. Pensamento Plural, 8(16), 25-45.

Instituto Brasileiro de geografia e estatística [IBGE]. (2017). Síntese dos Indicadores Sociais: Uma Análise das Condições de Vida da População Brasileira. Link

Lei n. 8.069 de 13 de julho de 1990. Dispõe sobre o Estatuto da Criança e do Adolescente. Link

Lei n. 12.243 de 02 de dezembro de 2010. Plano Nacional de Cultural. Link

Lei n. 13.257 de 08 de março de 2016. Marco Legal da Primeira Infância. Link

Lei n. 16.026 de 01 de junho de 2016. Plano Estadual de Cultura. Link

Lei n. 122 de 24 de agosto de 2017. Plano Estadual Cultura Infância. Link

Lei n. 16.856 de 22 de março de 2019. Programa Mais Infância. Link

Magistris, G. (2014). A infância na (e a partir da) América Latina: produção, instituições e políticas de infância. Desidades, 2(5), 32-37. 
Mantilla, L., Stolkiner, A., \& Minnicelli, M. (Orgs.). (2017). Biopolítica e infancia: Niños, niñas e instituciones en el contexto latinoamericano. México: Universidade de Guadalajara.

Marchi, R. C., \& Sarmento, M. J. (2017). Infância, normatividade e direitos das crianças: transições contemporâneas. Educação \& Sociedade, 38(141), 951-964.

Minayo, M. C. D. S. (2012). Análise qualitativa: Teoria, passos e fidedignidade. Ciência \& Saúde Coletiva, 17, 621-626.

Morais, R. L. S., Carvalho, A. M., Magalhães, L. C., \& Pinto, P. A. F. (2015). Primeira Infância e Pobreza no Brasil: uma análise integrada a partir de indicadores em saúde, educação e desenvolvimento social. Revista de Políticas Públicas, $19(1), 303-314$.

Passetti, E. (2000). Crianças carentes e políticas públicas. In M. Del Priori, História das crianças no Brasil (pp. 347-375). São Paulo: Contexto.

Programa Mais Infância Ceará. (2019). Programa Mais Infância Ceará. Fortaleza: Governo do Estado do Ceará.

Qvortrup, J. (2014). Visibilidade das crianças e da infância. Linhas Críticas, 20(41), 23-42.

Sarmento, M. J. (2004). As culturas da infância nas encruzilhadas da $2^{\mathrm{a}}$ modernidade. In M. J. Sarmento \& A. B. Cerisara, Crianças e miúdos: Perspectivas sociopedagógicas da infância e educação (pp. 9-34). Porto: Edições ASA.

Sarmento, M. J. (2006). Visibilidade social e estudo da infância. In V. M. R. Vasconcelos \& M. J. Sarmento (Orgs.), Infância (in) visivel (pp. 7-14). Rio de Janeiro: Vozes.

Sarmento, M. J. (2018). Infância e cidade: Restrições e possibilidades. Educação, 41(2), 232-240.

Sarmento, M. J., Fernandes, N., \& Tomás, C. A. (2007). Políticas públicas e participação infantil. Educação, Sociedade \& Culturas, 25(1), 183-206.

Tomás, C. (2007). "Participação não tem Idade": Participação das crianças e cidadania da infância. Contexto \& Educação, $22(78), 45-68$.

Unicef. (1989). Convenção Internacional dos Direitos da Criança. Link

\section{Como citar:}

Costa, E. A. G. A., Cavalcante, A. P. P. (2020). Políticas Públicas Culturais para as Infâncias Cearenses: Anúncio de Novos Ventos? Revista Subjetividades, 20(Esp 1. Relações Intergrupais: Preconceito e Exclusão Social), e8877. http://doi. org/10.5020/23590777.rs.v20iEsp1.e8877

\section{Endereço para correspondência}

Érica Atem Gonçalves de Araújo Costa

E-mail: ericaatem@yahoo.com.br

Andrea Pinheiro Paiva Cavalcante

E-mail: andrea@virtual.ufc.br 